\title{
Relationships Between Incidence and Severity of Fusarium Head Blight on Winter Wheat in Ohio
}

\author{
P. A. Paul, S. M. El-Allaf, P. E. Lipps, and L. V. Madden
}

Department of Plant Pathology, The Ohio State University, Ohio Agricultural Research and Development Center, Wooster 44691. Accepted for publication 8 May 2005.

\begin{abstract}
Paul, P. A., El-Allaf, S. M., Lipps, P. E., and Madden, L. V. 2005. Relationships between incidence and severity of Fusarium head blight on winter wheat in Ohio. Phytopathology 95:1049-1060.

To determine the relationship between incidence ( $I$; proportion of diseased spikes) and severity ( $S$; mean proportion of diseased spikelets per spike) for Fusarium head blight of wheat and to determine if severity could be predicted reliably from incidence data, disease assessments were made visually at multiple sample sites in artificially and naturally inoculated research and production fields between 1999 and 2002. Ten distinct data sets were collected. Mean disease intensity ranged from 0.023 to 0.975 for incidence and from 0.0003 to 0.808 for severity. A model based on complementary log-log transformation of incidence and severity performed well for all data sets, based on calculated coefficients of determination and random residual plots. The $I-S$ relationship was consistent among years and locations, with similar slopes for all data sets.
\end{abstract}

ABSTRACT
For 7 of the 10 data sets and for the pooled data from all locations and years, the estimated slope from the fit of the model ranged from 1.03 to 1.26. Time of disease assessment affected the relationship between incidence and severity; however, the estimated slopes from each assessment time were also close to 1 . Based on the width of the $95 \%$ prediction interval, severity was estimated more precisely at lower incidence values than at higher values. The number of sampling units and the index of dispersion of disease incidence had only minor effects on the precision with which $S$ was predicted from $I$. The estimation of mean $S$ from $I$ would substantially reduce the time required to assess Fusarium head blight in field surveys and treatment comparisons, and the observed relationship between $I$ and $S$ could be used to identify genotypes with some types of disease resistance.

Additional keywords: Fusarium graminearum, Gibberella zeae, Triticum aestivum.
Fusarium head blight of wheat (Triticum aestivum L.), caused primarily by Fusarium graminearum Schwabe (teleomorph: Gibberella zeae), has become a yield-limiting factor in many wheat and barley production regions in the United States and throughout the world $(1,27,30)$. Under disease-favorable conditions, infection of the spikes leads to poor grain fill and seed quality, resulting in yield losses due to reduced kernel size and weight, reduced seed germination, seedling blight, and poor stands $(1,27,30)$. The impact of this disease is further compounded by the fact that $F$. graminearum produces mycotoxins which pose a health threat to humans and livestock $(27,39)$. In addition, mycotoxin-contaminated grains may be rejected or devalued in commerce $(1,27)$.

Efforts to minimize the impact of Fusarium head blight have been centered around the use of management strategies such as host resistance, crop rotation, tillage, and fungicide application $(1,30)$. From a management perspective, the comparison of $\mathrm{Fu}-$ sarium head blight epidemics across years and locations is necessary to determine the effects of the environment on the efficacy of a given management approach, to compare the efficacy of different management approaches under similar environmental conditions, and to develop or recommend management strategies or decision thresholds. Through comparative epidemiology, fungicide efficiency and cultivar resistance can be tested, differences in $F$. graminearum populations identified, and the effects of weather factors on cultivar- $F$. graminearum interactions and Fusarium head blight development determined. In addition, data collected from multiple years and locations, representing a range of environmental conditions and disease levels, can be used to develop

Corresponding author: L. V. Madden; E-mail address: madden.1@osu.edu

DOI: 10.1094/PHYTO-95-1049

(c) 2005 The American Phytopathological Society
Fusarium head blight management decision-making tools such as risk assessment models (7). Inconsistencies in disease quantification, however, have made it difficult to fully utilize disease intensity data from multiple locations and years to compare epidemics and to develop comprehensive management programs.

In Fusarium head blight research, incidence, that is, the proportion of diseased spikes in a sample, and severity (sometimes referred to as disease index [40]), that is, the proportion of diseased spikelets per spike, are the commonly used measures of disease intensity. At the individual spike scale, incidence is a binary measurement $(25,46)$, meaning that it is a measure of only one of two possible states, diseased or not diseased. For a sample of spikes, incidence is a discrete variable, with proportions ranging from 0 to 1 . Incidence is quicker and easier to measure than severity, and measures of incidence are often more accurate, precise, and reproducible than measures of severity (3). Assessment of Fusarium head blight severity under field conditions is tedious, costly, and time-consuming and may be prone to bias and experimental error. Even when standard area diagrams $(13,40)$ are used to facilitate disease quantification, inaccurate severity assessments may still occur. Spike characteristics such as the number of spikelets per spike, presence or absence of awns, and chaff color may all affect a rater's perception of the actual proportion of spikelets diseased, leading to erroneous severity scores (4). Despite the drawbacks, however, severity is often considered a more important and useful measure of disease intensity than incidence for the evaluation of yield loss and for determining the effectiveness of disease management strategies (3). Since measures of incidence are more easily acquired and more reliable than measures of severity, and since severity is more useful than incidence for certain objectives, a quantitative relationship between incidence and severity would greatly facilitate the evaluation of disease intensity when accurate assessments of severity are not available or possible (34). 
Although incidence and severity are clearly defined (3), the distinction between these two measures is not always as apparent as the definitions suggest. Very often, what is referred to as incidence or severity depends on the sampling unit used during disease quantification (34). In Fusarium head blight quantification, this distinction is made even more difficult by the fact that disease may be assessed at different levels (field, plot, plant, tiller, spike, and spikelet) within a spatial hierarchy. What is commonly referred to as severity, mean proportion of diseased spikelets per spike, in a 20-spike sample (higher level of the spatial hierarchy), becomes incidence if each individual spikelet (lower level of the spatial hierarchy) is considered as the sampling unit. Essentially, the incidence-severity relationship represents a relationship between disease intensity measured at different levels of a spatial hierarchy (34).

Models for relationships between incidence and severity $(9,14$, $17,18,31-33,36,38,43)$ and relationships between measures of disease intensity at different levels of a spatial hierarchy $(16,26$, $28,41,43$ ) have been developed for several pathosystems. These relationships differ from one pathosystem to another and may be influenced by the cultivar and plant organ assessed, time of disease assessment during an epidemic, growing season, location, and treatment applied to the assessed plots (34). Thus, it would be imprudent to use these models to describe the relationship between incidence and severity of Fusarium head blight of wheat prior to thoroughly evaluating them over multiple years and locations under a range of cropping/management scenarios to ascertain which model provides consistently strong relationships between incidence and severity of this disease.

The relationship between measures of Fusarium head blight intensity at different levels of a spatial scale has been studied for spring wheat in the United States by Groth et al. (14) and for wheat grown under European conditions by $\mathrm{Xu}$ et al. (44). The former study focused mainly on the comparison of year-to-year repeatability of disease incidence, diseased head severity (mean proportion of infected spikelets per infected spike, or equivalently, mean relative area of infected spikes with symptoms), and disease index (equivalent to the standard definition of severity [3], as used here) as measures of components of resistance to Fusarium head blight. Groth et al. (14) did not fully explore the relationship between incidence and severity from the standpoint of its practical application in disease quantification and surveys, and how it may be influenced by sampling. While the work of Xu et al. (44) did address issues related to practical application of the relationship between incidence and severity of Fusarium head blight, as was the case in the study conducted by Groth et al. (14), the epidemiological conditions under which this study was conducted were different from those occurring commonly in winter wheat-producing areas of Ohio and the Midwest United States. Wheat cultivars planted in Europe and in spring wheat areas differ from those planted in Ohio; the composition of the Fusarium complex inciting Fusarium head blight in Europe is generally different from that found in Ohio (45), the latter being predominantly F. graminearum; and the way Fusarium head blight severity was quantified in the aforementioned studies differs from the way it is commonly done in Ohio. These factors may all influence the relationship between measures of disease intensity (34).

The objectives of this study were to (i) determine if there was a significant and consistent relationship between incidence and severity of Fusarium head blight of winter wheat in Ohio; (ii) determine whether severity could be predicted reliably from disease incidence data; and (iii) determine the effects of sampling for incidence on the precision of estimates of severity.

\section{MATERIALS AND METHODS}

Disease assessment sites. In order to acquire data from $\mathrm{Fu}-$ sarium head blight epidemics of different intensity and to repre- sent a range of environmental, cropping, and management conditions likely to influence the development of Fusarium head blight, several research plots and production fields were selected for Fusarium head blight assessment in Ohio during the 1999, 2000, 2001, and 2002 winter wheat growing seasons. Data were collected from disease-screening nurseries for Fusarium head blight resistance in all 4 years (labeled N99, N00, N01, and N02) and Fusarium head blight uniform fungicide trial plots in 2001 and 2002 (FG01 and FG02) at the Ohio Agricultural Research and Development Center (OARDC), Wooster; commercial wheat fields located at the OARDC (ComA and ComB) in 2002; and research plots located at the OARDC Northwest Agricultural Research Station (NWARS) near Hoytville (NWA and NWB) in 2001. Commercial wheat fields and research plots were naturally infected with $G$. zeae, while disease-screening nurseries and fungicide trial plots were infested artificially with $G$. zeaeinfested maize kernels.

Genotypes evaluated in the disease-screening nurseries included advanced breeding lines from the The Ohio State UniversityOARDC wheat-breeding program and check cultivars that ranged from highly susceptible to moderately resistant to G. zeae. Nurseries consisted of multiple 1-m-long, single-row plots, each planted with a different breeding line of wheat, in three or four blocks. Breeding lines were grouped into sets based upon the number of years they had been in the program and the degree of testing they had received. There was no relationship among sets for different years except that the lines that performed best for all agronomic characteristics were maintained in the breeding program over time. The moderately resistant cv. Freedom and susceptible cv. Pioneer 2545 were included in each set as checks. Nursery design, cultural practices, inoculation methods, and mist irrigation were as previously described (4).

The susceptible commercial wheat cv. Agripro Elkhart was evaluated 2 years in the Fusarium head blight uniform fungicide trials. Fungicide trials consisted of $1.7-\mathrm{m}$ by $4.6-\mathrm{m}$ plots in a randomized complete block design with three replicates. Seven and eight treatments were included, with an untreated control, in the tests conducted in 2001 (FG01) and 2002 (FG02), respectively. Each fungicide treatment was applied at flowering, Feekes growth stage (GS) 10.5.1 (21). Plot design, cultural practices, inoculation methods, mist irrigation, and fungicide application procedures were identical both years $(23,24)$. The two research plots evaluated at NWARS in 2001 were approximately $62 \mathrm{~m}$ by $185 \mathrm{~m}$ each, planted with the moderately susceptible cvs. Hopewell (NWA) and Glory (NWB). The two commercial fields evaluated in 2002 were planted with the moderately susceptible cvs. Dynasty (ComA) and Hopewell (ComB). The research plots and commercial fields were planted and managed using standard agronomic practices for their locations (22).

Disease quantification and data analysis. In each field/plot, incidence and severity were estimated visually at several systematically selected sampling sites using a two-stage cluster sampling approach. Assessments were made at 100 sampling sites in each research plot (NWA and NWB) and commercial field (ComA and ComB) and at 10 sites per replicate plot in each fungicide trial field (FG01 and FG02). In the disease-screening nursery, each plot (breeding line) was used as a sampling site, with a total of 144 (36 lines $\times 4$ replicates), 1,053 (351 lines $\times$ 3 replicates), 723 (241 lines $\times 3$ replicates), and 366 (122 lines $\times$ 3 replicates) plots (=sites) assessed in 1999, 2000, 2001, and 2002, respectively.

Each sampling site consisted of a section of a wheat row (a cluster), approximately $30 \mathrm{~cm}$ long, from which a sample of at least 20 spikes was evaluated in each disease-screening nursery, and at least 50 spikes in each fungicide trial plot, commercial wheat field, and research plot. Severity was estimated visually for each spike within each cluster. Incidence $(I)$ was recorded as the proportion of diseased spikes (number of spikes with nonzero 
severity divided by the total number of spikes sampled). Severity $(S)$ was recorded as the average proportion of diseased spikelets per spike (sum of the proportion of diseased spikelets per spike divided by the total number of spikes sampled, including those with zero severity). Note that the actual number of spikelets was not counted; rather a single estimate of the proportion of spikelets with symptoms was made for each spike. The average diseased head severity, $X$, can be calculated exactly from $S$ and $I$ using the relation $S=X \times I$ (40). Although Fusarium head blight researchers sometimes refer to $X$ as simply "severity" $(14,40)$, it is actually a form of conditional severity because its value is conditioned on the disease status of spikes (28). Here we restrict attention to (mean) severity for all spikes $(S)$ since this is the usual formulation for disease severity of a population (3). A single assessment was made at Feekes GS 11.2 (soft dough) in all plots except the fungicide trial plots in which disease intensity was quantified at three different times during the growing season in 2001 and four times in 2002.

Except for the nursery data, each pair of incidence and severity values from each sampling site was considered an observation for data analysis. The three or four replicates of disease intensity for each breeding line within each nursery were pooled to form an observation with 60 or 80 spikes (which is comparable to the number of spikes per sampling unit in the other data sets). The data were edited to remove observations with no diseased spikes (i.e., $I=0$ and $S=0$ ), since the $I-S$ relationship is only defined when disease is present.

Modeling the $\boldsymbol{I}-\boldsymbol{S}$ relationship. The data for each field and each year were subjected to separate linear ordinary least-squares regression analyses using PROC REG of SAS (SAS Institute, Cary, NC). For each analysis, values of $I$ and $S$ were used to fit the following model:

$$
\operatorname{CLL}(S)=\alpha+\beta \operatorname{CLL}(I)
$$

where $\alpha$ and $\beta$ are model parameters and $\operatorname{CLL}(\bullet)$ represents complementary log-log transformation of incidence, $\operatorname{CLL}(I)=$ $\ln [-\ln (1-I)]$, and of severity, $\operatorname{CLL}(S)=\ln [-\ln (1-S)]$. Several additional models for incidence-severity relationships were evaluated in a preliminary analysis (12; P. Paul, unpublished data) based on prior usage in the literature or on similarity to previously developed models for hierarchical relationships of disease intensity (28). However, these models were not subjected to further analysis herein based on the fact that they do not constrain $I$ and $S$ to be less than or equal to $1(100 \%)$, their residual plots (obtained when fitted to the data of the current study) were nonrandom (strongly funnel-shaped), or the shape of the curve for predicted $S$ versus $I$ deviated from that exhibited by the raw data. Equation 1 constrains both $I$ and $S$ to be between 0 and 1. A one-sided $t$ test was used to determine if the slope of equation 1 was larger than 1 , based on the estimated $\beta$ and its standard error (29). Model fit was evaluated based on coefficient of determination adjusted for degrees of freedom, $R_{a}^{2}$; squared correlation between $S$ and predicted $S(\hat{S})$, sometimes called $R^{* 2}(3)$; and randomness of the residual plots. Except for $R^{* 2}$, all statistics obtained from the linear regression analysis were calculated in terms of CLL-transformed $S$ values and measured the linearity of the relationship between the response and predictor transformed variables as well as the scatter about the predictions. In contrast, $R^{* 2}$ is a measure of the scatter of observed severity values around the predicted severity values (which were obtained by back-transformation of the predicted CLL values [described below]).

Since the fungicide experiments consisted of disease observations at several times, an additional analysis was performed with the selected model to determine the effect of time on the incidence-severity relationship. In particular, a covariance analysis was performed to determine the effect of sampling time on model parameters.
Precision in estimating $\boldsymbol{S}$ from $\boldsymbol{I}$. Based on the estimated parameters from the regression analysis, predicted values of the response variable (CLL-transformed $S$ ) were directly obtained, as well as a $95 \%$ prediction interval for response variable (29). Back-transformation of the predicted response variable and the end points of the prediction interval were calculated to obtain predictions and intervals for actual severity. If $\operatorname{CLL}(S)$ is the predicted transformed $S$ for a given data set, then predicted $S$ is given by

$$
\widehat{S}=1-\exp (-\exp (\hat{\operatorname{CLL}}(S)))
$$

The estimate of $S$ at a given $I$ is slightly biased because $\widehat{S}$ is a nonlinear function of $\operatorname{CLL}(S)$. However, based on a Taylor series expansion and large-sample theory (2), the bias for this model is, on average, $<0.02$ (L. V. Madden, unpublished data) using the estimated parameters and the mean square error (MSE) from the fit of the linear model. The upper and lower limits of the $95 \%$ prediction interval for $\operatorname{CLL}(S)$ is given by $\operatorname{CLL}(S) \pm 2 \sqrt{V}$, where $V$ is the variance of $\operatorname{CLL}(S)$ based on estimated parameters of the model, which is the sum of the MSE for the fitted model and the estimated variance of the expected (i.e., mean) $\operatorname{CLL}(S)$ at a given value of CLL(I) (29). The prediction interval for $S$ was calculated as

$$
\begin{aligned}
& \widehat{S}_{U}=1-\exp (-\exp (\operatorname{CLL}(S)+2 \sqrt{V})) \\
& \widehat{S}_{L}=1-\exp (-\exp (\operatorname{CLL}(S)-2 \sqrt{V}))
\end{aligned}
$$

Because of the nonlinear transformation, the interval is not symmetric around $\widehat{S}$, but is constrained to lie between 0 and 1 .

Effect of sampling on prediction of $S$. One direct application of an $I-S$ model is to estimate severity from a survey of disease incidence. Then, the uncertainty in the calculated $I$ must be accounted for in determining a prediction interval for $S$. That is, the equation for $V$ must be expanded to incorporate possible variation in $I$ used in the model. The uncertainty of $I$ can be represented by the estimated variance of mean $I$ in a sample of $N$ sampling units (groups or clusters of spikes) and $n$ spikes per sampling unit. The variance is written as $I(1-I) D /(n N)$, where $D$ is the index of dispersion, a measure of the degree of heterogeneity in a sample $(25,26)$. A random pattern (which corresponds to a binomial distribution) is indicated by $D=1$. Previously, when data were collected in the same manner as in this study, it was found that $D$ for this disease was between 0.44 and 2.00 for fields with low disease intensity (incidence $<0.28$ ) and low levels of within-field inoculum (6), and between 0.88 and 4.50 for fields with moderate to high disease intensity (mean incidence ranging from 0.02 to 0.69 ) and high levels of within-field inoculum (11).

There are several approaches for accounting for uncertainty of $I$ when predicting $S$. Jones (20) provides a thorough review and synthesis of this topic, for simple random sampling of insects, and the relationship between log of insect density and CLL-transformation of the proportion of sampling units with insects, which is similar to our CLL(S)-CLL(I) model. Utilizing the same arguments as in Jones (20), but for our cluster sampling situation and the CLL $(S)$-CLL $(I)$ model, a good approximation of $V$ is given by

$$
\hat{V} \approx\left(\frac{\hat{\beta}^{2}}{(1-I) \ln (1-I)^{2}}\right) D \frac{I}{n N}+\mathrm{MSE}
$$

Equation 4 was used for $V$ in equations $3 a$ and $3 b$ to obtain prediction intervals for disease severity under a range of theoretical sampling situations. In particular, the effects of number of sampling units $(N)$, under the control of the sampler, and index of dispersion $(D)$, a property of the epidemic, on the widths of the prediction intervals were determined for selected model fits. 


\section{RESULTS}

Disease development. Fusarium head blight intensity varied across locations and years and within each data set (Fig. 1). Overall, disease incidence per sampling unit (not per data set) ranged from 0.023 to 0.975 , while mean disease severity per sampling unit ranged from 0.0003 to 0.808 . Averaged across all sampling sites within each data set, the highest mean incidence and severity were recorded in the N01 (incidence $=0.74$ ) and FG02 (severity = 0.31 ) data sets, respectively (Fig. 1). The range of disease severity values was widest for the N01 data set $(0.001$ to 0.81$)$ and narrowest for the ComA data set $(0.004$ to 0.27$)$. The narrowest and widest ranges of incidence values were observed in the FG02 (0.43 to 0.87 ) and ComA (0.02 to 0.95 ) data sets, respectively.

In general, Fusarium head blight severity increased curvilinearly as incidence increased (Figs. 2 and 3; A, C, E, and G). For all data collected from screening nurseries, for a given value of disease incidence, a range of severity values was observed (Fig. $2 \mathrm{~A}, \mathrm{C}, \mathrm{E}$, and $\mathrm{G})$. This range was narrowest at incidence values $<0.2$ and became wider with increasing incidence. Compared with the nursery data sets, a slightly different trend was observed for the relationship between incidence and severity for data collected from research plots (Fig. 3A and C), commercial fields (Fig. 3E and $\mathrm{G}$ ), and fungicide trial plots (Fig. 4A and E). For these latter data sets, there was a more linear increase in severity with in- creasing incidence (up to an incidence of $\approx 0.8$ ), and the range of severity values at a given incidence value was narrower than that observed for the nursery data sets.

Modeling the I-S relationship. The CLL transformation of both $I$ and $S$ (Figs. 2, 3, and 4; B, D, F, and H) was particularly useful for obtaining a linear relationship (on a transformed scale) and explaining a reasonably high percentage of the variation in transformed $S$. Regression analysis of severity on incidence indicated that the percentage of the variation in transformed severity explained by incidence varied from one data set to another (Table 1). Based on the value of $R_{a}^{2}$, the CLL $(S)$-CLL $(I)$ model fitted well to most of the data sets. More than $75 \%$ of the variation in transformed $S$ was explained by the variation in $I$ for all but two data sets (FG02 and N02) (Table 1). In general, the $R_{a}^{2}$ values were highest for data collected from commercial wheat fields (ComA and ComB), followed by research plots (NWA and NWB), fungicide trial plots (FG01), and disease-screening nurseries (N99, N00, N01, and N02). Similar results were obtained for model fit comparisons using $R^{* 2}$ instead of $R_{a}^{2}$.

Both parameter estimates for equation 1 were highly significant for all data sets (Table 1). Estimated slopes $(\beta)$ and intercepts $(\alpha)$ varied somewhat from one data set to another, suggesting a variation in the relationship between $I$ and $S$ among data sets. Estimated intercepts ranged from -2.624 to -1.119 . For 7 of the 10 data sets, collected in different years under different cropping

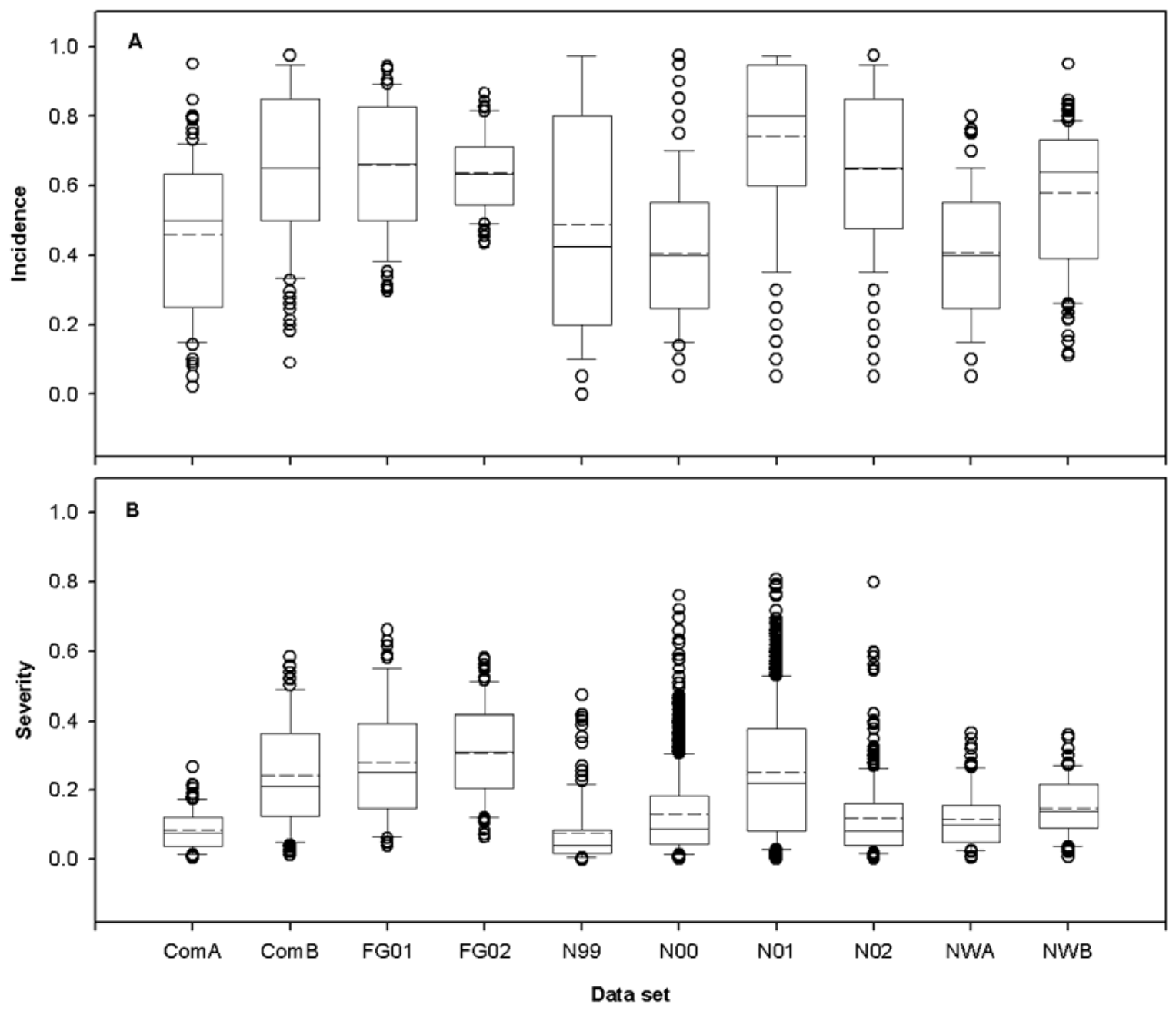

Fig. 1. Box plots summarizing the distribution of $\mathbf{A}$, incidence and $\mathbf{B}$, severity of Fusarium head blight of wheat for 10 data sets. The broken and solid lines within the box represent the mean and median, respectively, while the top and bottom lines of the box represent the 75th and 25th percentiles of the data, respectively. Vertical bars extending beyond the boxes represent the 10th and 90th percentiles, and circles indicate outliers. ComA and ComB $=$ commercial wheat fields A and B; FG01 and FG02 = 2001 and 2002 fungicide trial plots; N99, N00, N01, and N02 = 1999, 2000, 2001, and 2002 Fusarium head blight screening nurseries; and NWA and NWB $=$ research plots $\mathrm{A}$ and $\mathrm{B}$. 
conditions, the rates of increase in $S$ with increasing $I$ on a CLL scale (i.e., estimated $\beta$ values) were similar. For these data sets, the estimated slope ranged from 1.03 to 1.26 (Table 1). Eight of the ten slopes were significantly larger than $1(P<0.05)$ even though their estimates were near 1 . In general, slopes and intercepts were estimated more precisely (i.e., low standard errors) for data collected from commercial wheat fields and Fusarium head blight screening nurseries in 2000 and 2001 than for the other data sets. For the N00 and N01 nurseries, this was partly because of the higher number of observations analyzed, since these data sets also had the highest MSE values.

The estimated $\beta$ values were larger for the fungicide data sets than for most of the other data sets (Table 1). However, unlike the other data sets, disease was measured at multiple times during the fungicide studies. Based on analysis of covariance of the data from fungicide trial plots, time of disease quantification had a significant effect on the intercept in both $2001(F=305.58, P<$ $0.001)$ and $2002(F=77.30, P<0.001)$. The interaction between
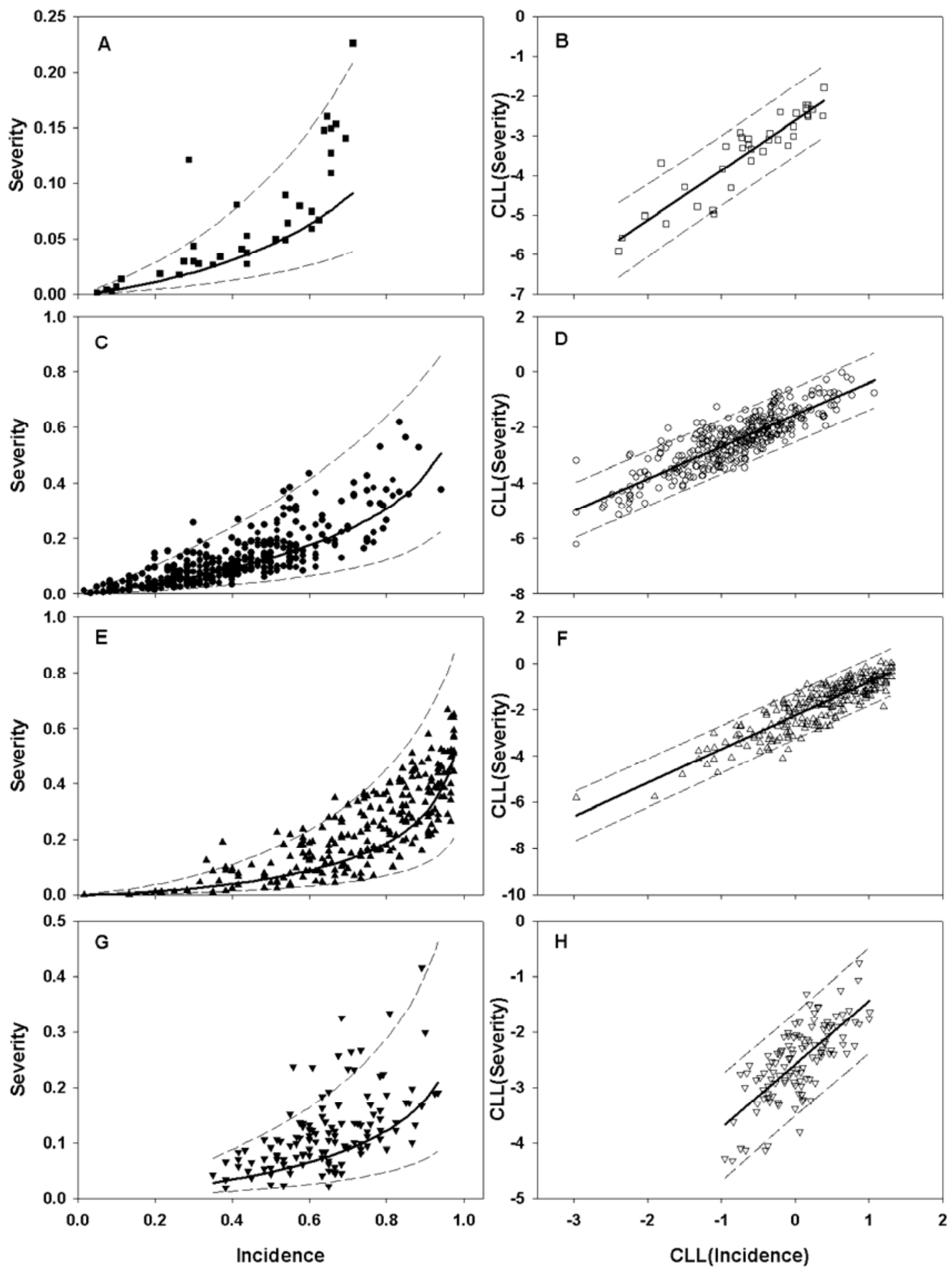

Fig. 2. Relationship between incidence and severity of Fusarium head blight of wheat for untransformed (A, C, E, G) and complementary log-log transformed (B, D, F, H) data from the $1999(\mathbf{A}, \mathbf{B}), 2000(\mathbf{C}, \mathbf{D}), 2001(\mathbf{E}, \mathbf{F})$, and $2002(\mathbf{G}, \mathbf{H})$ wheat screening nurseries for Fusarium head blight resistance. Each point represents the mean value from a sample of at least 60 spikes assessed at Feekes growth stage 11.2 (soft dough). Solid lines represent back-transformed predicted severity $(\mathbf{A}, \mathbf{C}, \mathbf{E}, \mathbf{G})$ and complementary $\log$-log transformed predicted severity $(\mathbf{B}, \mathbf{D}, \mathbf{F}, \mathbf{H})$, while dashed lines represent the upper and lower limits of the $95 \%$ prediction intervals for back-transformed $(\mathbf{A}, \mathbf{C}, \mathbf{E}, \mathbf{G})$ and transformed predicted severity $(\mathbf{B}, \mathbf{D}, \mathbf{F}, \mathbf{H})$. 
the covariate $\operatorname{CLL}(I)$ and time of disease quantification was also significant in $2001(F=4.26, P=0.020)$ and $2002(F=3.91, P=$ 0.013). Despite the interaction effect, however, very similar slopes were observed for each assessment time in both years, except for the earliest assessment in 2002 (Table 2, Fig. 4D and H). The remaining slopes were close to 1 and similar to those estimated for the other data sets. The estimated intercepts ranged from -2.01 to -1.06 and -1.68 to -0.74 in 2001 and 2002 , respectively.
Because of the similarity of results for the different data sets, the model was fitted to the pooled data (Table 1). The estimated slope was very close to (but significantly larger than) 1 , and the estimated intercept was -1.73 . As expected, the $R_{a}^{2}$ and $R^{* 2}$ statistics were lower for the pooled data than for most of the individual data sets because of the combining of data. Seventytwo percent of the variation in transformed $S$ was explained by the model for the pooled data. Also, because of the larger number of
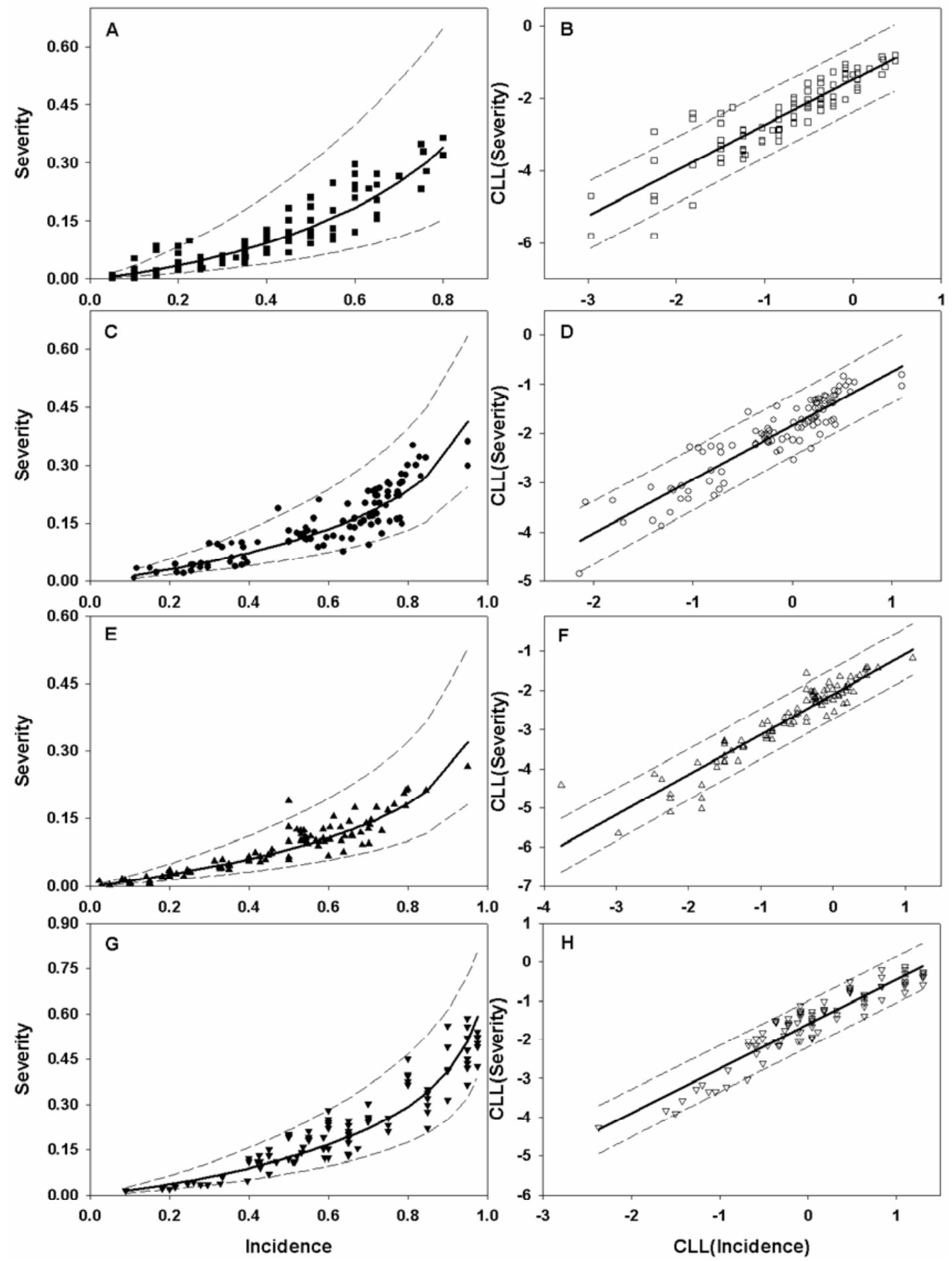

Fig. 3. Relationship between incidence and severity of Fusarium head blight of wheat for untransformed (A, C, E, G) and complementary log-log transformed (B, $\mathbf{D}, \mathbf{F}, \mathbf{H})$ data from two research plots, NWA $(\mathbf{A}, \mathbf{B})$ and NWB $(\mathbf{C}, \mathbf{D})$, and two commercial wheat fields, ComA $(\mathbf{E}, \mathbf{F})$ and ComB $(\mathbf{G}, \mathbf{H})$. Each point represents the mean value from a sample of at least 50 spikes assessed at Feekes growth stage 11.2 (soft dough). Solid lines represent back-transformed predicted severity (A, $\mathbf{C}, \mathbf{E}, \mathbf{G})$ and complementary $\log -\log$ transformed predicted severity $(\mathbf{B}, \mathbf{D}, \mathbf{F}, \mathbf{H})$, while dashed lines represent the upper and lower limits of the $95 \%$ prediction intervals for back-transformed $(\mathbf{A}, \mathbf{C}, \mathbf{E}, \mathbf{G})$ and transformed predicted severity $(\mathbf{B}, \mathbf{D}, \mathbf{F}, \mathbf{H})$. 
observations, standard errors of estimated parameters were very low for the pooled data.

Predicting $S$ from $I$ and effect of sampling on prediction of $S$. The model was used to predict Fusarium head blight severity from observed incidence, and the $95 \%$ prediction interval for severity at each incidence value was determined using equations $3 \mathrm{a}$ and $3 \mathrm{~b}$ with the statistics in Table 1 . Severity was estimated more precisely at lower incidence values than at higher values.
For all data collected from Fusarium head blight screening nurseries, the width of the $95 \%$ prediction interval increased as incidence increased up to the maximum observed incidence in each data set (Fig. 2A, C, E, and G). For example, with the N99 data set (Fig. 2A), for $I=0.10, \hat{S}$ was 0.004 and the width of the $95 \%$ prediction interval $(W$, the difference between equations $3 \mathrm{a}$ and $3 b$ ) equaled 0.01 ; for $I=0.40, \hat{S}=0.03$ and $W=0.06$; for $I=$ $0.60, \hat{S}=0.06$ and $W=0.12$; and for $I=0.90, \hat{S}=0.19$ and $W=$
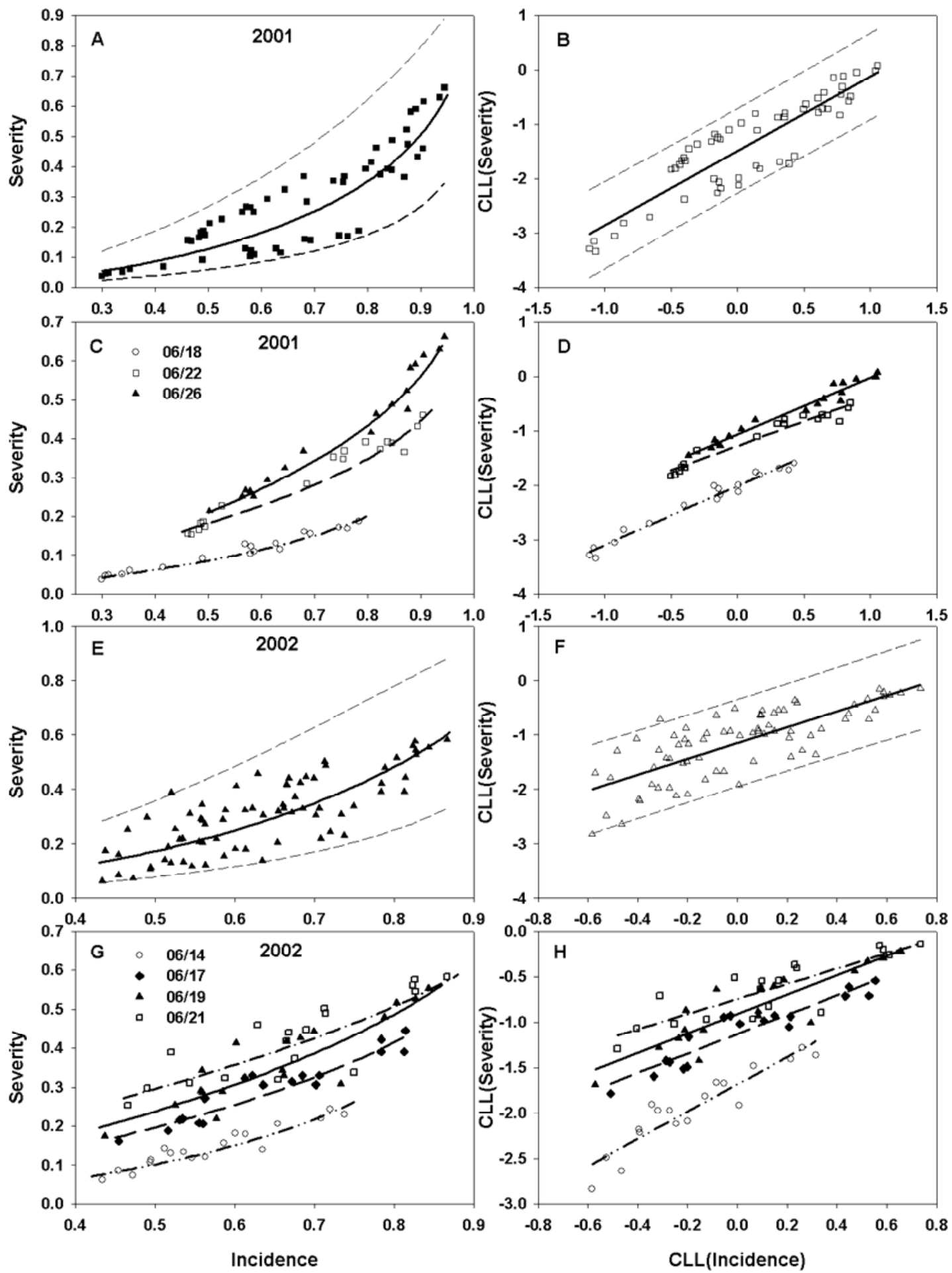

Fig. 4. Relationship between incidence and severity of Fusarium head blight of wheat for untransformed (A, C, E, G) and complementary log-log transformed (B, D, F, H) data from the 2001 (A, B, C, D) and 2002 (E, F, G, H) Fusarium head blight Uniform Fungicide trial plots. Each point represents the mean value for each replicate of each treatment and assessment time across 10 sampling units. At least 50 spikes were sampled at each site. In $\mathbf{A}, \mathbf{B}, \mathbf{E}$, and $\mathbf{F}$, solid lines represent back-transformed predicted severity $(\mathbf{A}, \mathbf{E})$ and complementary log-log transformed predicted severity $(\mathbf{B}, \mathbf{F})$, while dashed lines are the upper and lower limits of the $95 \%$ prediction intervals for back-transformed $(\mathbf{A}, \mathbf{E})$ and transformed predicted severity $(\mathbf{B}, \mathbf{F})$. In $\mathbf{C}, \mathbf{D}, \mathbf{G}$, and $\mathbf{H}$, lines represent back-transformed predicted severity $(\mathbf{C}, \mathbf{G})$ and transformed predicted severity $(\mathbf{D}, \mathbf{H})$ for each assessment time (coded with different shapes and specified in $\mathbf{C}$ and $\mathbf{G})$. 
0.32 . Similar trends were observed for data collected from the 2000, 2001, and 2002 nurseries (Fig. 2C, E, and G), research plots (Fig. 3A and C), commercial wheat fields (Fig. 3E and G), and fungicide trial experiments (Fig. 4A and E).

When the uncertainty in incidence was considered (i.e., using equation 4 for $V$ in equations $3 a$ and $3 b$ ), the number of sampling units $(N)$ and the index of dispersion $(D)$ only had marginal effects on the precision with which severity was estimated from incidence. For all data sets, for the CLL $(S)$-CLL $(I)$ model, varying $N$ from 5 to 75 and $D$ from 1 to 5 in equation 4 resulted in very subtle changes in the widths of the $95 \%$ prediction intervals. As exemplified for the data set from a commercial wheat field (Fig. 5), for $N=10$, increasing $D$ from 1 to 5 resulted in slightly wider prediction intervals (Fig. 5A). Conversely, for a fixed $D=$ 3 , increasing $N$ from 5 to 75 led to a slight decrease in the widths of the prediction intervals (Fig. 5B). The combinations of $D=1$ and $N=75$, and $D=5$ and $N=5$, resulted in the narrowest and widest intervals, respectively (Fig. 5C). The reason for the insensitivity to changes in $D$ and $N$ was that MSE was, on average, eight times larger (for the ComA data set) than the first term of equation 4 , so that changes in $D$ and $N$ could not have much of an effect on $\hat{V}$. For the other data sets, MSE was between 7 and 39 times larger than the first term of equation 4.

\section{DISCUSSION}

A highly significant relationship between incidence and severity of Fusarium head blight was observed for all data sets at each location in each year. Despite the variation in severity at a given incidence, the relationship was fairly consistent among data sets. The model based on CLL-transformation of incidence and severity (equation 1) performed consistently well on all data sets, explaining between 52 and $89 \%$ of the variation in severity on a CLL scale. The squared correlation between $S$ and predicted $S$ was between 0.33 and 0.87 . As expected, severity was estimated more precisely at lower incidence values than at higher values, based on the width of the severity prediction interval (equations $3 \mathrm{a}$ and $3 \mathrm{~b}$ ). It should be noted that a significant relationship does not necessarily mean that precision is high enough (e.g., that the prediction interval is narrow enough) for a model to be used for predictions, since achieved significance level is highly influenced by number of observations. Draper and Smith (pages 129-134 in literature citation 10) showed that in order for the regression equation to be useful, the calculated (i.e., achieved) $F$ value statistic from a model fit (Table 1) needs to be at least four or five times larger than the critical $F$ value $\left(F^{*}\right)$ for a significant result at the chosen probability value (such as $P=0.05$ ). With the number of observations being analyzed here, $F^{*}=4$ for a significant fit at $P=$ 0.05 for all but the smallest data set. The smallest achieved $F$ value was 102.9 , which was 25 times larger than $F^{*}$ (i.e., $102.9 / 4=25.7$ for the FG02 data set). Clearly, by this standard, the fitted $\operatorname{CLL}(S)-\operatorname{CLL}(I)$ model had sufficient precision for predictions as well as for describing the relationship between severity and incidence.

Several other models evaluated during the preliminary data analysis (12) provided satisfactory fit for several data sets. In particular, models based on simple square-root transformation of $S$ (and no transformation of $I$ ), and angular transformation of $S$ and $I$, and also $\log$ transformation of $S$ and $I(28)$ resulted in $R_{a}^{2}$ and

TABLE 2. Estimated intercepts and slopes and their corresponding standard errors for the relationship between complementary log-log transformed incidence $(C L L(I))^{\mathrm{a}}$ and complementary $\log -\log$ transformed severity $(C L L(S))^{\mathrm{b}}$ of Fusarium head blight of wheat for different disease assessment times in 2001 and 2002

\begin{tabular}{|c|c|c|c|c|c|c|}
\hline \multirow[b]{2}{*}{ Year } & \multirow{2}{*}{$\begin{array}{c}\text { Assessment } \\
\text { time }^{\mathrm{c}}\end{array}$} & \multicolumn{4}{|c|}{$C L L(I) / C L L(S)^{\mathrm{d}}$} & \multirow[b]{2}{*}{$I_{S 10}{ }^{\mathrm{e}}$} \\
\hline & & $\hat{\alpha}$ & $\operatorname{se}(\hat{\alpha})$ & $\hat{\beta}$ & $\operatorname{se}(\hat{\beta})$ & \\
\hline \multirow[t]{3}{*}{2001} & 18 June & -2.012 & 0.028 & $1.085 * \mathrm{f}$ & 0.047 & 0.56 \\
\hline & 22 June & -1.274 & 0.026 & 0.897 & 0.048 &.$- \mathrm{g}$ \\
\hline & 26 June & -1.060 & 0.031 & 1.042 & 0.051 &.$- \mathrm{g}$ \\
\hline \multirow[t]{4}{*}{2002} & 14 June & -1.683 & 0.049 & $1.497 *$ & 0.155 & 0.50 \\
\hline & 17 June & -1.131 & 0.041 & 1.066 & 0.130 &.$- \mathrm{g}$ \\
\hline & 19 June & -0.913 & 0.041 & 1.067 & 0.122 &.$- \mathrm{g}$ \\
\hline & 21 June & -0.744 & 0.043 & 0.833 & 0.117 & $--\mathrm{g}$ \\
\hline
\end{tabular}

a $\ln (-\ln (1-I))$

b $\ln (-\ln (1-S))$.

c In each year, the final assessment time corresponds to Feekes growth stage 11.2 (soft dough).

${ }^{d}$ Estimates of the intercept ( $\left.\hat{\alpha}\right)$ and slope $(\hat{\beta})$, and standard error (se) of the estimates for the relationship between $C L L(I)$ and $C L L(S)$.

e Incidence of Fusarium head blight corresponding to $10 \%$ severity.

$\mathrm{f} *$ Indicates that slope is significantly greater than $1(P<0.05)$ based on a one-sided $t$ test. All slopes are significantly different from $0(P<0.05)$.

$\mathrm{g}$ The lowest observed severity was $>10 \%$ at these times, so corresponding incidence was not calculated.

TABLE 1 . Summary of the regression analyses of the relationship between $C L L(I)^{\mathrm{a}}$ and $C L L(S)^{\mathrm{b}}$ of Fusarium head blight of wheat for 10 data sets

\begin{tabular}{|c|c|c|c|c|c|c|c|c|c|c|}
\hline \multirow[b]{2}{*}{ Data set $\left(\right.$ year) ${ }^{\mathrm{c}}$} & \multirow[b]{2}{*}{ Obs. $^{d}$} & \multicolumn{8}{|c|}{ Statistics ${ }^{\mathrm{e}}$} & \multirow[b]{2}{*}{$I_{S 10}{ }^{\mathrm{f}}$} \\
\hline & & $\hat{\alpha}$ & $\operatorname{se}(\hat{\alpha})$ & $\hat{\beta}$ & $\operatorname{se}(\hat{\beta})$ & $R_{a}^{2}$ & $R^{* 2}$ & MSE & $F$ value & \\
\hline ComA (2002) & 100 & -2.085 & 0.0401 & 1.028 & 0.0379 & 0.882 & 0.864 & 0.104 & 736.2 & 0.57 \\
\hline ComB (2002) & 100 & -1.605 & 0.0299 & $1.144 * \mathrm{~g}$ & 0.0399 & 0.892 & 0.868 & 0.089 & 822.2 & 0.43 \\
\hline FG01 (2001) & 54 & -1.490 & 0.0534 & $1.369 *$ & 0.0921 & 0.806 & 0.816 & 0.150 & 220.8 & 0.44 \\
\hline FG02 (2002) & 72 & -1.119 & 0.0465 & $1.478 *$ & 0.1456 & 0.594 & 0.631 & 0.156 & 102.9 & 0.37 \\
\hline N99 (1999) & 36 & -2.624 & 0.0939 & $1.256^{*}$ & 0.0953 & 0.832 & 0.758 & 0.188 & 173.8 & 0.73 \\
\hline N00 (2000) & 350 & -1.543 & 0.0396 & $1.148 *$ & 0.0352 & 0.753 & 0.669 & 0.248 & $1,062.8$ & 0.42 \\
\hline N01 (2001) & 241 & -2.261 & 0.0378 & $1.451 *$ & 0.0488 & 0.786 & 0.665 & 0.267 & 883.6 & 0.63 \\
\hline N02 (2002) & 122 & -2.584 & 0.0428 & 1.143 & 0.1003 & 0.516 & 0.325 & 0.221 & 129.8 & 0.73 \\
\hline NWA (2001) & 100 & -1.478 & 0.0654 & $1.255^{*}$ & 0.0617 & 0.807 & 0.853 & 0.206 & 413.9 & 0.42 \\
\hline NWB (2001) & 100 & -1.837 & 0.0326 & $1.089 *$ & 0.0474 & 0.842 & 0.797 & 0.099 & 528.1 & 0.49 \\
\hline Pooled -- & 1,275 & -1.728 & 0.0167 & $1.069 *$ & 0.0188 & 0.717 & 0.656 & 0.317 & $3,225.3$ & 0.46 \\
\hline
\end{tabular}

${ }^{a}$ Complementary log-log transformation of Fusarium head blight incidence, $\ln (-\ln (1-I))$.

b Complementary log-log transformation of Fusarium head blight severity, $\ln (-\ln (1-S))$.

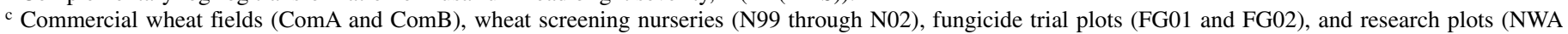
and NWB).

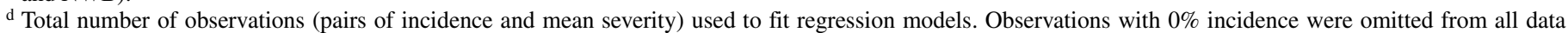
sets because then severity is also 0, by definition. For the FG01 and FG02 data sets, Obs. represents pooled observations from three replicates of six treatments assessed at three and four times during 2001 and 2002, respectively.

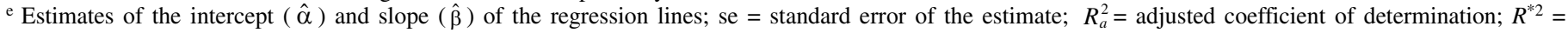
squared correlation between actual severity and back-transformed predicted severity; MSE $=$ mean square error; and $F$ value $=F$ statistic from the regression analysis of variance. All $F$ values were highly significant $(P<0.001)$, meaning that $\hat{\beta}$ was different from 0 .

${ }^{\mathrm{f}}$ Incidence of Fusarium head blight corresponding to $10 \%$ severity.

$\mathrm{g} *$ Indicates that slope is significantly larger than $1(P<0.05)$ based on a one-sided $t$ test. All slopes are significantly $(P<0.05)$ different from 0 . 
$R^{* 2}$ values comparable to those resulting from the fit of the $\operatorname{CLL}(S)$-CLL $(I)$ model. However, none of these models constrains predicted severity to be $\leq 1(100 \%)$, so they were not further used. In addition, part of the problem with the arcsine-based model proposed by Groth et al. (14) for relationship between conditional severity and $I$ on spring wheat was that it predicted a reversesigmoid shape for severity versus incidence, which was not exhibited by our data.

According to Seem (34), the three basic interrelated approaches commonly used to derive relationships between incidence and severity for plant diseases are (i) correlation and regression methods; (ii) multiple infection methods; and (iii) measurement of aggregation and representative discrete distribution. We opted to use the first approach to derive relationships between incidence and severity for Fusarium head blight of winter wheat in Ohio. The problem of nonuniform variances (alluded to by Seem [34]) associated with the use of regression methods was minimized through data transformation. A previous attempt to develop models describing the relationship between different measures of Fusarium head blight intensity focused on the statistical distribution of disease entities, such as number of spikes and spikelets diseased (44). The key step in this approach is using the parameters of the distribution to estimate the probability of a zero (i.e., the probability of being disease-free [15]). Hughes et al. (16) and McRoberts et al. (28) suggested that when severity is considered to be a continuous variable, as was done in this study (because of the use of a visual scale for proportion of diseased spikelets per spike, rather than the direct counting of diseased and disease-free spikelets), the use of an empirical curve-fitting approach is appropriate to establish a functional relationship between the two measures of disease intensity. This is because there is inadequate knowledge of the statistical distribution of severity as a continuous random variable $(15,28)$.

Although empirical, equation 1 provided a biologically meaningful representation of disease intensity of wheat spikes $(I)$ and spikelets $(S)$ in a population. This can be seen by expressing equation 1 in nonlinear form:

$$
S=1-\exp \left(-q(-\ln (1-I))^{\beta}\right)
$$

in which $q=\exp (\alpha)$. Equation 5 is equivalent to the prediction equation 2 (but without the "hats" for parameter estimates, since we are not restricting attention to just specific fits of the model). When $\beta=1$, equation 5 reduces to $S=1-(1-I)^{q}$, a common model for discrete disease data at multiple hierarchical scales in a canopy (16), with $q<1$ (or $\alpha<0$ ). Hughes et al. (15) explain how, when $\beta=1, q$ is an empirical metric related to (in our case) the magnitude of severity at a given incidence and also a parameter of the incomplete beta function related to the relative area of Fusarium head blight severity per spike. Treating $\beta$ as an unknown constant (to be estimated) adds to the flexibility of equation 5. The parameters $q$ and $\beta$ jointly control both the shape and steepness of the severity-incidence curve, although only the latter affects the steepness of the CLL-CLL line. Equation 5 and its special case $(\beta=1)$ describe a relationship where $S$ initially increases slowly with increasing $I$, followed by more rapid increase in $S$ with $I$ at high $I$. This agrees with our results for Fusarium head blight (Figs. 2 to 4), as well as with results from other studies $(9,17,18,31,35)$. More formally, this relationship of the two disease intensities can be characterized by using the rate of increase in $S$ with unit increase in $I(d S / d I)$ at a fixed time, which is given by

$$
\frac{d S}{d I}=\frac{q \beta(-\ln (1-I))^{\beta}}{(I-1) \ln (1-I)} \exp \left(-q(-\ln (1-I))^{\beta}\right)
$$

$d S / d I$ was $<1$ over most of the range of incidence for the 10 data sets (L. V. Madden, unpublished data); with the parameter estimates in this study, $d S / d I$ only exceeded 1 at an incidence of $\approx 0.8$ or higher for most data sets. Figure 6 shows an example of estimated $d S / d I$ for the ComA and ComB data sets.

Equation 5 is undefined at both severities and incidences of 0 and 1 . More formally, $S$ goes to 0 as $I$ approaches 0 in the limit, and $S$ goes to 1 as $I$ approaches 1 in the limit, which completes the range specification for $I-S$. In a sample (in contrast to the population), however, it is possible to obtain 0 or 1 for incidence (or severity), which can present complications in data analysis. As mentioned previously, observations with $I=0$ (and thus, $S=0$ ) should be removed before data analysis, since the $I-S$ relationship is defined when disease is present. There are several possible analytical approaches when $I=1$ for one or more observations. The first is simply to remove the observations. This can be

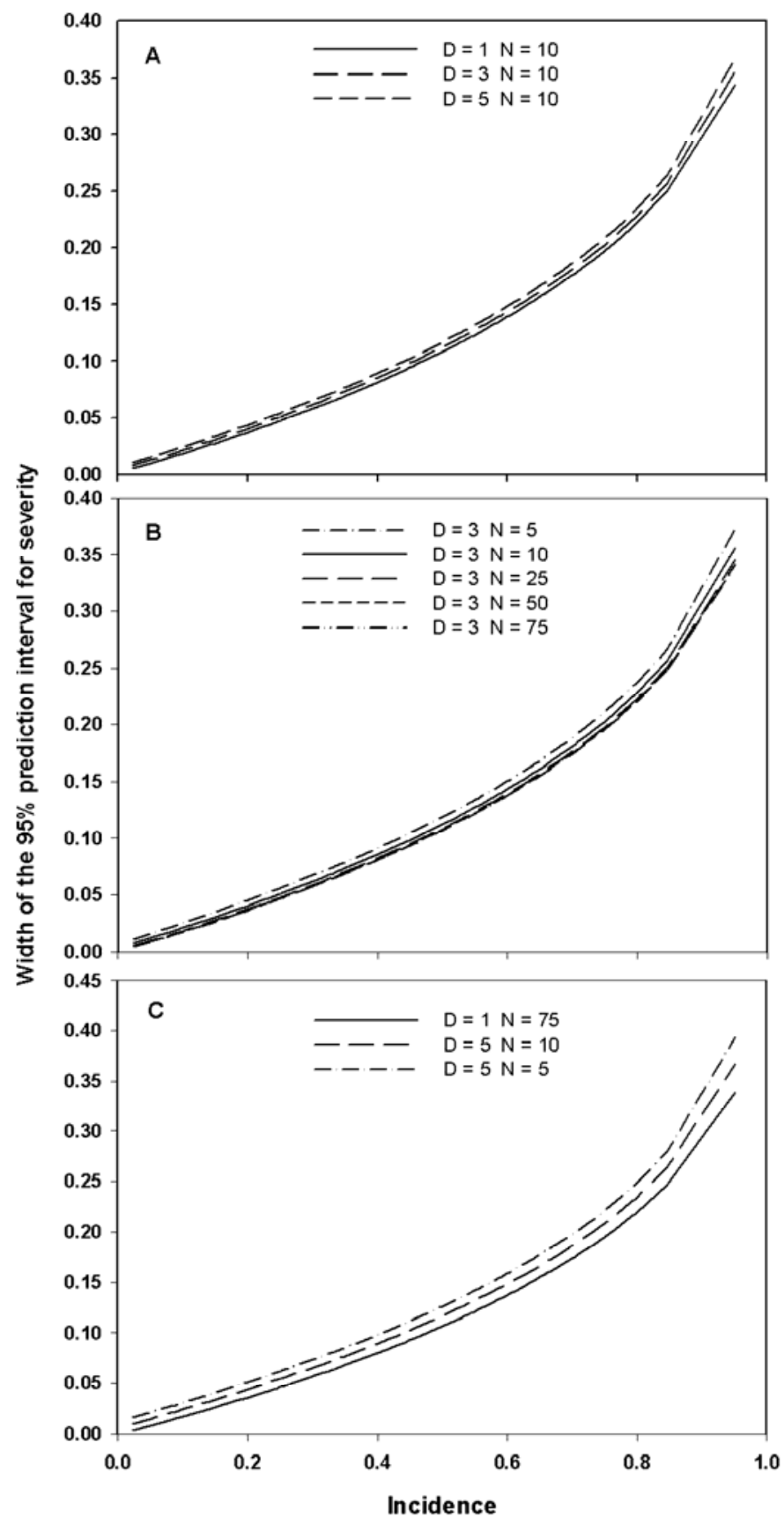

Fig. 5. Plots of the widths of the $95 \%$ prediction interval for predicted severity of Fusarium head blight of wheat for a range of indices of dispersion $(D)(\mathbf{A})$, sampling units $(N)(\mathbf{B})$, and combinations of $D$ and $N(\mathbf{C})$. Results based on regression results for the ComA data set (Table 1), with number of spikes per sampling unit $(n)$ equal to 50 . 
justified by the fact that when all spikes in the sample are diseased (but not necessarily all the spikes in the population), there is no longer any information on the magnitude of (mean) severity in relation to incidence, other than being larger than the (mean) severity when some spikes are disease-free. In this extreme situation, severity and diseased head severity are the same. Conversely, one can adjust incidence values prior to model fitting $(5,29)$. For instance, one can convert any $I=1$ value to a large value slightly less than 1 (generally, half-way between the largest observed $I$ not equal to 1 and 1 [e.g., 0.995 if incidence values of $I=0.99$ are possible]). Alternatively, all incidence values can be redefined as $I^{*}=$ (number of diseased spikes $\left.+1 / 2\right) /($ number of observed spikes +1$)$, and one can use $I^{*}$ in place of $I$ in the regression analysis. These latter approaches are commonly used in statistical packages. With 30 or more observations and a wide range of incidence values in a data set, all of these approaches likely will result in very similar parameter estimates.

Even though the CLL $(S)$-CLL $(I)$ model performed well on all data sets, based on the values of the regression coefficients, there was some variation in the relationship between incidence and severity. Similar variations in severity in relation to incidence were observed for other pathosystems $(9,17,18,31,36-38)$ and were attributed to differences among growing seasons or locations/ weather conditions $(18,36,38)$, genotype resistance response (31), distance from the source of inoculum (31), time of disease quantification during an epidemic (31), and fungicide application (37). For the CLL $(S)$-CLL $(I)$ model, there was a remarkable similarity of the slopes (on the transformed scale), with the absolute values of estimated $\beta$ being slightly (and frequently significantly) above 1 for most of the data sets and for the pooled data set. Even for the fungicide studies, $\hat{\beta}$ was found to be $\approx 1$ when time of assessment was accounted for (Table 2). These results were similar to those reported by Xu et al. (44) for the relationship between CLLtransformed spikelet and spike incidence levels of Fusarium head blight in Europe, where a different Fusarium complex is found (45). Solving equation 16 of $\mathrm{Xu}$ et al. (44) for spikelet incidence (comparable with severity as defined in our study) yielded a slope

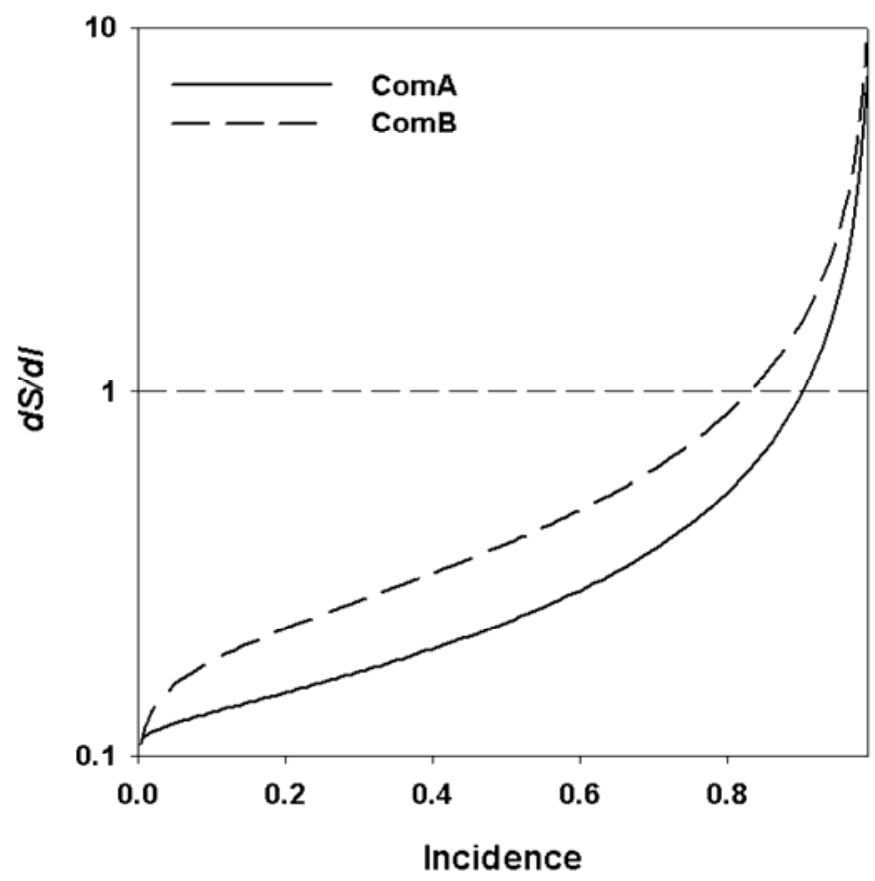

Fig. 6. Rate of increase in severity $(S)$ with unit increase in incidence $(I)$ $(d S / d I)$ of Fusarium head blight of wheat at a fixed assessment time for data collected from two commercial wheat fields (ComA and ComB). Curves based on equation 6, with parameter estimates in Table 1 (and $q$ calculated as $\exp (\alpha))$. of 1.156 and an intercept of -2.313 , very similar to our results in Table 1 . The variation among the data sets primarily was in terms of the estimated intercepts, reflecting height differences in the CLL $(S)$-CLL $(I)$ lines.

With similar slopes, differences in estimated intercepts of the $\operatorname{CLL}(S)-\operatorname{CLL}(I)$ relationship reflect, in part, differences in mean $\operatorname{CLL}(S)$ at a given value of $\operatorname{CLL}(I)$. For instance, the increasing (transformed) severity of disease with time (at a given transformed incidence) can be seen with the fungicide data sets (Table 2). For the other data sets, ComA, N99, N01, and N02 had relatively low $\hat{\alpha}$ values compared with the others. However, this does not necessarily indicate that overall mean $\operatorname{CLL}(S)$ (or mean $S$ ) was lower than that for the other data sets (Fig. 1), because a low overall mean $S$ can occur simply when mean incidence is low. No obvious year or location effects on the heights of the CLL $(S)$ CLL $(I)$ lines, as determined by $\hat{\alpha}$, were observed.

The low value of $d S / d I$ over most of the incidence range (Fig. 6) has important consequences for temporal progress of severity and incidence. Using the arguments in Hughes et al. (16), if $d I / d t$ is the rate of increase in incidence, then the rate of increase in severity is given by

$$
\frac{d S}{d t}=\left(\frac{d I}{d t}\right) \cdot\left(\frac{d S}{d I}\right)
$$

Whenever $d S / d I$ is $<1$, the temporal rate $d S / d t$ must be less than $d I / d t$, no matter what equation is used for $d I / d t$. Ultimately, $d S / d t$ will exceed $d I / d t$ when most spikes are already infected but there is still a substantial area of each spike unaffected by the disease. Differences in the rates of increase in incidence and severity have been attributed to the occurrence of two distinct types of infection, allo- and auto-infection (34) for polycyclic diseases. An increase in incidence results from allo-infection (spread among plant units - spikes), whereas an increase in mean severity within a sampling unit results from both allo- and auto-infection (spread within infected plant units - spikelets). Using simulation models, Willocquet and Savary (42) demonstrated that the time taken for maximum disease incidence $(I=1)$ to occur decreased with increasing allo-infection. However, in the case of Fusarium head blight, which normally functions as a monocyclic disease, the infection of new disease-free spikes from primary inoculum (analogous to allo-infection) was probably higher than the spread within infected spikes (analogous to auto-infection), at least until most spikes were infected, resulting in a lower severity than incidence (and $d S / d I<1$ ). Jeger et al. (19) suggested that increase in disease incidence over time was related to the availability of inoculum. Pataky and Headrick (31) reported that the relationship between incidence and severity for common rust of sweet corn varied with distance from a source of inoculum. Because Fusarium head blight is a monocyclic disease, inoculum density certainly will influence incidence level. In the wheat nurseries, high inoculum density and misting probably led to an initially high incidence (relative to severity); only when incidence approached 1 was there a large change in severity with unit increase in incidence.

The genotypes planted during the 4 years of this study varied from year to year and from one location to another. In particular, the wheat breeding lines planted in some nurseries varied greatly in resistance to Fusarium head blight. Resistance to Fusarium head blight may be characterized as two main types, resistance to infection (type I) and resistance to colonization of the spike (type II) (1), and the relative difference between the two types among reactions of genotypes may affect the relationship between incidence and severity. Cultivars that are equally resistant to infection (type I resistance) may in fact have different resistance response to the spread of the fungus within the infected spikes (type II resistance); hence, for any given incidence value, a wide range of severity values may be observed across genotypes. This could explain the generally higher variation (e.g., larger MSE) for the 
nursery data sets than for the others (Table 1). As discussed by McRoberts et al. (28), results of incidence-severity analysis are directly useful in evaluating resistance response. In particular, the incidence-severity relationship could be used to draw conclusions about the relative rate of disease increase among genotypes with different levels of resistance. Genotypes with unusually large $S$ at a given $I$ value would be indicative of those that allow for a high degree of colonization within spikes (analogous to auto-infection), whereas those with unusually low $S$ at a given $I$ would be indicative of genotypes that limit the degree of fungal colonization within spikes. We evaluated this with the nursery data sets by identifying observations that fell outside the prediction interval (P. Paul and L. V. Madden, unpublished data). There were three or four replicate plots of each wheat line, and we did not find any genotypes in which two or more of the replicate $S$ values were above $\hat{S}_{U}$ or below $\hat{S}_{L}$.

For genotypes with similar levels of type I and II resistance, differences in weather conditions across locations and years may have resulted in differences in the spread of the fungus within spikes (severity) even when comparable levels of primary infection occurred. Groth et al. (14) also hypothesized that differences between incidence and diseased head (i.e., conditional) severity (mean proportion of infected spikelets per infected spike) of Fusarium head blight on spring wheat were due to the fact that weather conditions were more conducive to primary infection than to spread within diseased spikes.

Fusarium head blight severity was predicted more precisely at lower incidence values than at higher values based on the widths of the prediction intervals for $S$. This was consistent with other studies (34). This reflected the fact that at low disease intensity, there was less variation in observed severities, or equivalently, greater proportionality between incidence and severity. As incidence increased, however, the range of severity values at a given incidence value also increased (at least over the range of severity and incidence values measured), leading to less precise predictions of severity from incidence. This was particularly true for data collected from Fusarium head blight screening nurseries. The decreasing precision can be attributed, at least in part, to the natural variation in any random variable ranging from 0 to 1 , with the greatest variation occurring around $0.5(25)$.

The number of sampling units $(N)$ and index of dispersion $(D)$ had little effect on the precision with which severity was predicted from incidence. This has importance in application of the derived models in survey sampling. Because of the variation in $S$ values at a given $I$, neither large variation in $I$ (measured by high $D$ ) or small number of samples had much of an effect on the width of the prediction interval for $S$. Thus, the incidence-severity relationship found in this study can be applied to a wide range of sampling results for incidence.

Using the relationship between incidence and severity, management decision thresholds may be established. For instance, Dillard and Seem (9) proposed an incidence of 0.8 , which corresponds to a mean severity of 0.01 , as an action threshold for rust of maize. A 0.1 mean severity value was used by De Wolf et al. $(7,8)$ as being indicative of the occurrence of a major epidemic of Fusarium head blight of wheat. According to the model based on CLL-transformation of incidence and severity, 0.1 mean severity corresponded to an incidence of 0.37 to 0.57 for all data sets except the 1999, 2001, and 2002 nurseries (Table 1). Although there was some variation in the incidence-severity relationship among data sets, the width of the prediction interval for $S$ around $0.1 \%$ was fairly narrow, except for some of the nursery data sets, where genotypes with different susceptibilities were planted. Thus, the precise estimation of mean severity or the upper prediction limit $\left(\hat{S}_{U}\right)$ from incidence would be reasonable at low severities.

The estimation of mean severity from incidence would substantially reduce the work load in Fusarium head blight quanti- fication in field surveys and treatment comparisons. It is less time-consuming than direct assessment of severity and generally requires less training of assessors (3). Once assessors can distinguish between diseased and diseased-free spikes, incidence can be quantified reliably at multiple locations, and large data sets can be acquired in relatively little time. This should greatly facilitate the comparison of epidemics in treatment evaluations, field surveys, and some resistance screening. In breeding programs where potentially thousands of early-generation lines are assessed for Fusarium head blight reaction, the estimation of incidence, and not severity, would save considerable resources. However, if one specifically wanted to identify and quantify the two major types of resistance to Fusarium head blight, one would want to measure both incidence and severity explicitly. Nonetheless, characterizing the functional relationship between incidence and severity is still critically important, because through this relationship researchers can identify the genotypes with unusually large or small severities for a given incidence (28), or through covariance analysis (when there are several pairs of $I-S$ points for each genotype), identify genotypes with an unusual $I-S$ relationship compared with others.

\section{ACKNOWLEDGMENTS}

Salaries and research support were provided by state and federal funds, especially the United States Wheat and Barley Scab Initiative, to the Ohio Agricultural Research and Development Center, The Ohio State University. We thank N. McRoberts of the Department of Plant Biology at The Scottish Agricultural College, Scotland, UK, for critically reviewing an earlier version of this manuscript and W. Bardall and A. Johnston for preparing and maintaining field plots.

\section{LITERATURE CITED}

1. Bai, G., and Shaner, G. 1994. Scab of wheat: Prospects for control. Plant Dis. 78:760-766.

2. Binns, M. R., Nyrop, J. P., and van der Werf, W. 2000. Sampling and Monitoring in Crop Protection: The Theoretical Basis for Developing Practical Decision Guides. CAB International, Wallingford, UK.

3. Campbell, C. L., and Madden, L. V. 1990. Introduction to Plant Disease Epidemiology. John Wiley \& Sons, New York.

4. Campbell, K. A. G., and Lipps, P. E. 1998. Allocation of resources: Sources of variation in Fusarium head blight screening nurseries. Phytopathology 88:1078-1086.

5. Collett, D. 2003. Modelling Binary Data. 2nd ed. Chapman \& Hall/CRC, New York.

6. Del Ponte, E. M., Shah, D. A., and Bergstrom, G. C. 2003. Spatial patterns of Fusarium head blight in New York wheat fields suggest role of airborne inoculum. Published Online. Plant Health Progress DOI:10.1094/PHP-2003-0418-01-RS.

7. De Wolf, E. D., Madden, L. V., and Lipps, P. E. 2003. Risk assessment models for wheat Fusarium head blight epidemics based on within-season weather data. Phytopathology 93:428-435.

8. De Wolf, E. D., Molineros, J., Wei, C., Lipps, P. E., Madden, L. V., and Francl, L. 2003. Development and deployment of the next generation prediction models for Fusarium head blight. Pages 125-128 in: Proc. Natl. Fusarium Head Blight Forum, 2003. U.S. Wheat and Barley Scab Initiative (USWBSI), East Lansing, MI.

9. Dillard, H. R., and Seem, R. C. 1990. Incidence and severity relationships for common maize rust on sweet corn. Phytopathology 80:842-846.

10. Draper, N., and Smith, H. 1981. Applied Regression Analysis. 2nd ed. John Wiley \& Sons, New York.

11. El-Allaf, S. M., Madden, L. V., and Lipps, P. E. 2001. Spatial pattern of scab incidence during Fusarium head blight epidemics on winter wheat in Ohio. Pages 18-22 in: Proc. Natl. Fusarium Head Blight Forum, 2001. U.S. Wheat and Barley Scab Initiative (USWBSI), East Lansing, MI.

12. El-Allaf, S. M., Madden, L. V., and Lipps, P. E. 2003. Incidence-severity relationships for Fusarium head blight on wheat. (Abstr.) Phytopathology 93(suppl.):S23.

13. Engle, J. S., Lipps, P. E., and Mills, D. 2003. Fusarium head blight severity scale for winter wheat. Ohio State University Extension Fact Sheet. Online Publication/AC-49-03.

14. Groth, J. V., Ozmon, E. A., and Busch, R. H. 1999. Repeatability and relationship of incidence and severity measures of scab of wheat caused by Fusarium graminearum in inoculated nurseries. Plant Dis. 83:10331038. 
15. Hughes, G., McRoberts, N., and Madden, L. V. 2004. Daamen's incidence-severity relationship revisited. Eur. J. Plant Pathol. 110:759-761.

16. Hughes, G., McRoberts, N., Madden, L. V., and Gottwald, T. R. 1997. Relationships between disease incidence at two levels in a spatial hierarchy. Phytopathology 87:542-550.

17. Imhoff, M. W., Leonard, K. J., and Main, C. E. 1982. Analysis of disease progress curves, gradients, and incidence-severity relationships for field and phytotron bean rust epidemics. Phytopathology 72:72-80.

18. James, W. C., and Shih, C. S. 1973. Relationships between incidence and severity of powdery mildew and leaf rust on winter wheat. Phytopathology 63:183-187.

19. Jeger, M. J., Jones, D. G., and Griffiths, E. 1983. Disease spread of non-specialized fungal pathogens from inoculated point sources in intraspecific mixed stands of cereal cultivars. Ann. Appl. Biol. 102:237244.

20. Jones, V. P. 1994. Sequential estimation and classification procedures for binomial counts. Pages 175-205 in: Handbook of Sampling Methods for Arthropods in Agriculture. L. P. Pedigo and G. D. Buntin, eds. CRC Press, Boca Raton, FL.

21. Large, E. C. 1954. Growth stages in cereals. Plant Pathol. 3:128-129.

22. Lipps, P., Beuerlein, J., Loux, M., Lentz, E., and Eisley, B. 2001. Improving wheat yields in Ohio. Ohio State University Extension. Online Publication 11/01-8M-193538.

23. Lipps, P. E., El-Allaf, S. M., and Johnson, A. L. 2002. Evaluation of foliar fungicides for control of Fusarium head blight on winter wheat in Ohio, 2001. Fungic. Nematicide Tests 57:CF14.

24. Lipps, P. E., El-Allaf, S. M., and Johnson, A. L. 2003. Evaluation of foliar fungicides for control of Fusarium head blight on winter wheat in Ohio, 2002. Fungic. Nematicide Tests 58:CF002.

25. Madden, L. V., and Hughes, G. 1995. Plant disease incidence: Distributions, heterogeneity, and temporal analysis. Annu. Rev. Phytopathol. 33:529-564.

26. Madden, L. V., and Hughes, G. 1999. An effective sample size for predicting plant disease incidence in a spatial hierarchy. Phytopathology 89:770-781.

27. McMullen, M., Jones, R., and Gallenburg, D. 1997. Scab of wheat and barley: A re-emerging disease of devastating impact. Plant Dis. 81:13401348.

28. McRoberts, N., Hughes, G., and Madden, L. V. 2003. The theoretical basis and practical application of relationships between different disease intensity measures in plants. Ann. Appl. Biol. 142:191-211.

29. Neter, J., Kutner, M. H., Wasserman, W., and Nachtsheim, C. J. 1996. Applied Linear Regression Models. McGraw-Hill/Irwin, Chicago, IL.

30. Parry, D. W., Jenkinson, P., and McLeod, L. 1995. Fusarium ear blight (scab) in small grain cereals-A review. Plant Pathol. 44:207-238.
31. Pataky, J. K., and Headrick, J. M. 1988. Relationships between common rust incidence and severity on a susceptible and a partially resistant sweet corn hybrid. Phytopathology 78:1155-1160.

32. Price, T. V., and Williams, B. L. 1990. Studies of the severity and incidence of Paspalum leaf blight. Aust. J. Agric. Res. 41:377-392.

33. Rayner, R. W. 1961. Measurement of fungicidal effects in field trials. Nature 190:328-330.

34. Seem, R. C. 1984. Disease incidence and severity relationships. Annu. Rev. Phytopathol. 22:133-150.

35. Seem, R. C., and Gilpatrick, D. 1977. Incidence and severity of powdery mildew on apple in relation to disease assessment. (Abstr.) Proc. Am. Phytopathol. Soc. 4:156.

36. Seem, R. C., and Gilpatrick, D. 1980. Incidence and severity relationships of secondary infections of powdery mildew on apple. Phytopathology 70:851-854.

37. Seem, R. C., Gilpatrick, D., and Pearson, R. C. 1981. Fungicide influence on the relationship between incidence and severity of powdery mildew on apple. Phytopathology 71:947-950.

38. Silva-Acuna, R., Maffia, L. A., Zambolim, L., and Berger, R. D. 1999. Incidence-severity relationships in the Coffea arabica-Hemileia vastatrix. Plant Dis. 83:186-188.

39. Snijders, C. H. A. 1990. Fusarium head blight and mycotoxin contamination of wheat, a review. Neth. J. Plant Pathol. 96:187-198.

40. Stack, R. W., and McMullen, M. P. 1998. A visual scale to estimate severity of Fusarium head blight in wheat. NDSU Extension Service: Small Grains Publications. Online Publication/PP-1095.

41. Turechek, W. W., and Madden, L. V. 2003. A generalized linear modeling approach for characterizing disease incidence in a spatial hierarchy. Phytopathology 93:458-466.

42. Willocquet, L., and Savary, S. 2004. An epidemiological simulation model with three scales of spatial hierarchy. Phytopathology 94:883-891.

43. Xu, X., and Madden, L. V. 2002. Incidence and density relationships of powdery mildew on apple. Phytopathology 92:1005-1014.

44. Xu, X.-M., Parry, D. W., Edwards, S. G., Cooke, B. M., Doohan, F. M., Maanen, A., Brennan, J. M., Monaghan, S., Moretti, A., Tocco, G., Mule, G., Hornok, L., Giczey, G., Tatnell, J., Nicholson, P., and Ritieni, A. 2004. Relationship between the incidences of ear and spikelet infection of Fusarium ear blight in wheat. Eur. J. Plant Pathol. 110:959-971.

45. Xu, X.-M., Parry, D. W., Nicholson, P., Thomsett, M. A., Simpson, D., Edwards, S. G., Cooke, B. M., Doohan, F. M., Brennan, J. M., Moretti, A., Tocco, G., Mule, G., Hornok, L., Giczey, G., and Tatnell, J. 2005. Predominance and association of pathogenic fungi causing Fusarium ear blight in wheat in four European countries. Eur. J. Plant Pathol. 112:143-154.

46. Zadoks, J. C., and Schein, R. D. 1979. Epidemiology and Plant Disease Management. Oxford University Press, New York. 